\title{
V2 - Monitoramento genético como controle de qualidade da Vacina de Febre Amarela I7DD e casos de eventos adversos
}

Cristiane Pinheiro Pestana ${ }^{1 *}$; Rafael Lawson Ferreira ${ }^{2}$; Ricardo Galler ${ }^{1}$; Marcos da Silva Freire ${ }^{1}$; Marco Alberto Medeiros ${ }^{1}$.

1 - Bio-Manguinhos/FIOCRUZ;

2 - INCQS/FIOCRUZ

\section{Introdução:}

Atualmente disponibilizada por sete fornecedores, a vacina $17 \mathrm{D}$ de febre amarela (VFA) foi elaborada em 1937 e 20 a 60 milhões de doses são administradas por ano. Duas linhagens principais são utilizadas para sua produção: 17D-204 e 17DD. A vacina produzida por Bio-Manguinhos contem a cepa 17DD, oriunda de passagens subsequentes do vírus $17 \mathrm{D}$ na $195^{\mathrm{a}}$ subcultura. A vacina $17 \mathrm{D}$ é considerada uma das mais seguras e eficazes já produzida, entretanto, raros eventos adversos neuro e viscerotrópicos são identificados. A variabilidade genética entre os vírus selvagens e vacinais são bem conhecidas permitindo diferenciá-los molecularmente.

\section{Objetivo:}

Desenvolver um protocolo para identificação molecular do vírus $17 \mathrm{D}$ vacinal por sequenciamento do genoma completo e demonstrar seu potencial como ferramenta no monitoramento genético do vírus vacinal e em casos de eventos adversos associados à vacinação antiamarílica.

\section{Metodologia:}

Entre 2012 e 2014, foram sequenciados 43 lotes vacinais, o lote semente 993FB013Z (lote atual de produção), e RNA viral oriundo de um caso de efeito adverso. Para o sequenciamento do genoma completo do vírus 17DD, 54 oligonucleotídeos foram desenhados utilizando ferramentas in silico. Em seguida 9 reações utilizando alguns dos oligos descritos anteriormente, foram padronizadas para a amplificação do RNA viral por RT-PCR. O sequenciamento foi realizado com o Kit Big Dye Terminator v3.1 Cycle Sequencing, e as eletroforeses capilares foram conduzidas no sequenciador automático Genetic Analyzer 3500XL. Para as análises in silico utilizamos o programa DNASTAR 5.05. 


\section{Resultados:}

As sequências nucleotídicas dos genomas analisados foram completamente elucidadas em duas cadeias. Todos os RNAs avaliados apresentaram o número de nucleotídeos característico (10.862 pb). O genoma dos lotes vacinais e do material oriundo de efeito adverso exibiram $100 \%$ de identidade nucleotídica com o vírus semente, e consequentemente, o alinhamento da poliproteína não evidenciou troca de aminoácidos. Os dados gerados pela análise nucleotídica de 43 lotes VFA 17DD demostram estabilidade genética da vacina e reprodutibilidade e robustez do protocolo desenvolvido pelo grupo. Em relação ao caso fatal de evento adverso nossos resultados corroboram os dados da literatura, nos quais, a ausência de mudanças nucleotidicas específicas sugere que fatores inerentes ao hospedeiro são os principais determinantes da gravidade do quadro clínico pós-vacinal.

\section{Conclusão:}

O método desenvolvido mostrou-se uma ferramenta para o monitoramento da variabilidade genética dos lotes da VFA 17DD e casos de eventos adversos associados. A literatura vigente e nossos achados reforçam que a VFA é uma vacina segura e eficaz e com alta estabilidade genética durante o processo de produção e após administração in vivo. Adicionalmente, um estudo mais aprofundado e robusto poderia avaliar a troca dos ensaios de neurovirulência em macacos pelo sequenciamento viral para a validação de lotes sementes para a produção de vacina, corroborando as orientações atuais de substituir os ensaios em animais por testes in vitro.

Palavras-Chave: Vacina de Febre Amarela, vírus 17DD, evento adverso, sequenciamento nucleotídico, controle de qualidade. 